\title{
EDITORIAL
}

\section{A Foreword from the Editor-in-Chief}

\section{Inna Reddy Edara*}

Graduate Institute of Educational Leadership and Development, Fu Jen Catholic University, Taiwan, Republic of China.

\section{ARTICLE INFO}

Article history

Received: 13 March 2019

Accepted: 14 March 2019

Published: 30 April 2019
$\mathrm{O}$ $\mathrm{n}$ behalf of the Bilingual Publishing Co., the editorial board and the staff, I welcome you to the inaugural issue of Journal of Psychological Research $(J P R)$, a peer-reviewed and an international open access academic journal, focusing on the multidisciplinary aspects of the field of psychology.

Bilingual Publishing Co. (BPC), located in Singapore, since its beginnings in 1984, has been dedicated to bilingual academic research, publishing international journals, and organizing conferences. Since its foundation, the BPC has been continuously garnering a high reputation in Southeast Asian countries and around the world. The obvious reason is that the BPC is sternly aware of the ever advancing technology and the rapidly changing developments in the use of digital media that summon for a change in attitude and methodology of researching and learning, with a special emphasis on the need for high-quality academic achievements. Therefore, the BPC's mission has been centered on discerning the changing needs of the academic world and committed to advancing the research around the world by publishing the latest research in various academic fields and ensuring that the resources are accessible in print, digital, and online formats.

There are currently a large number of scientific journals in the world that inclusively or exclusively publish the academic research in the fields of psychology. Yet, despite growing interest in the fields of psychological research and applications, there exists a lack of accessibility of publication channels for the Southeast Asian scholars in particular and for the worldwide researchers in general. In this situation, the BPC has taken up an additional mission of starting this new journal to give an appropriate access to the academicians and researchers of psychology to share their outstanding achievements with the world.

Journal of Psychological Research (JPR) is a peer-reviewed and an international open access academic journal, which focuses on the multidisciplinary aspects of the study of psychology, including but not limited to Psychoanalysis, Cognitive Neuroscience, Clinical Psychology, Applied Psychology, Experimental Psychology, Social Psychology, Developmental Psychology, Counselling Psy-

*Corresponding Author:

Inna Reddy Edara,

Editor-in-Chief of Journal of Psychological Research; Graduate Institute of Educational Leadership and Development, Fu Jen Catholic University, 510 Zhongzheng Road, Xinzhuang District, New Taipei City, 24205 Taiwan, Republic of China;

E-mail:065049@mail.fju.edu.tw 
chology, Educational Psychology.

Given the multidisciplinary scope of this journal's contents and to ensure that the submitted research manuscripts across the various disciplines covered by the JPR can be reviewed on time by the experts in the appropriate discipline, the management team has been striving to invite an editorial board of at least 100 professionals, representing the distinct fields of psychology and various academic institutions and geographical localities. At the time of formulating this editorial, there were already 58 members on the editorial board, which truly is a great achievement in a short period of time.

To set the highest possible academic and publishing standards from the onset, the JPR has put in place a stringent peer-review process in order to uphold the high quality of papers published in this journal and ensure that the reporting of research work is truthful and precise. After the proper review process, this inaugural issue is ready for publication with four research articles. The first article on "Psychological Stress among Business Travelers in Malaysia" ${ }^{,[1]}$ investigated the underlying biopsychosocial factors, such as health concern, burnout, and social support to explain stress among business travelers in Malaysia. The authors conducted the mediation analyses, which showed that only burnout mediated the relationship between business travel and perceived stress, suggesting that emotional, mental, and physical exhaustion due to depletion of energy resources validly explains the relation between the less intense business travels and the increased psychological stress. In other words, business travelers who traveled less intensely were more vulnerable to travel stress due to burnout.

In the second article on "Imagination in Entrepreneurship: An Inspiration from Heidegger, ${ }^{,[2]}$, the authors studied that the imagination, as informed by Heidegger, has important implications for entrepreneur's business success and management. The authors explain that Heidegger's imagination is a mode of engaging with challenges we face when our pathways and life projects breakdown, which propel us to build new possible solutions by creatively imagining things. The authors cite the examples of Steve Jobs, Mark Zuckerberg, and Jack Ma in explaining the role of imagination in successful entrepreneurship.

In the third article on "Beyond Bloom's: Students' Perception of Bloom's Taxonomy and its Convolution with Cognitive Load" ${ }^{,[3]}$, the authors explained the use of Bloom's Taxonomy in categorizing the cognitive skills to answer the exam questions that are labeled as high-level and low-level in their difficulty. Their research suggested that students consistently ranked high-level questions incorrectly. Based on Cognitive Load Theory, the authors suggested that it is the cognitive load that prevents students from accurately assessing the cognitive level of an exam question, which points to the need for instructors to eliminate cognitive load while designing the exam questions.

The final article on "Functional Expansion of Music Education Technologies: The Example of Music Rehabilitation Therapy of Neurology Ward Patients" ${ }^{\text {"[4] }}$ discussed the possible role of music education activities in rehabilitation of patients with neurodegenerative disease. Specifically, the authors developed a music psychotherapy program for rehabilitation of patients with Parkinson's neurodegenerative disease. First, the authors analyzed main symptoms of Parkinson's neurodegenerative disease, and then suggested physical restriction, emotional deprivation, and social deprivation as target objects for music rehabilitation therapy. The authors concluded that this pilot experiment with music rehabilitation therapy for patients suffering with a neurodegenerative Parkinson's disease demonstrated significant effect on all levels of manifestations of symptoms.

Finally, on the occasion of the publication of this inaugural issue, I would like to thank all the people who had a vision to create Journal of Psychological Research. In particular, I thank the Bilingual Publishing Co. and the management team for inviting me to be the first Editor-in-Chief of JPR. I also thank all the members of the editorial board for their willingness to serve the Journal in their respective capacities. Finally, I thank all the authors who contributed their research to this inaugural issue.

While feeling happy as this inaugural issue is brought out, I am are aware that Journal of Psychological Research requires commitment, not only from the publishers and editors but also from the reviewers and the manuscript contributors. Without the vision of the publishers and support of the editorial team and members, this Journal would not have come into existence. Without the contributions from the authors, it is not possible to continue the Journal. Hence, I want to encourage the authors to submit to Journal of Psychological Research your research manuscripts, review articles, case studies, as well as short communications and discussion in all fields of psychology.

\section{References}

[1] Dhiviya Karunaharan, Psychological Stress among Business Travelers in Malaysia[J]. Journal of Psychological Research, 2019, 1(1): 4-14

[2] Usman Talat and Kirk Chang, Imagination in Entrepreneurship: An Inspiration from Heidegger[J]. Journal of Psychological Research, 2019, 1(1):15-23.

[3] Jamie Lee Jensen, Andrea J. Phillips and Jace C. 
Briggs, Beyond Bloom's: Students' Perception of Bloom's Taxonomy and its Convolution with Cognitive Load[J]. Journal of Psychological Research, 2019, 1(1):24-32.

[4] Tatiana Vladimirovna Lvova and Alla Vladimirovna
Toropova, Functional Expansion of Music Education Technologies (through the example of music rehabilitation therapy of neurology ward patients)[J]. Journal of Psychological Research, 2019, 1(1):33-36. 